\title{
Estrogens, the be-all and end-all of male hypogonadal bone loss?
}

\author{
M. R. Laurent • E. Gielen • D. Vanderschueren
}

Received: 13 June 2014 / Accepted: 19 August 2014 / Published online: 7 November 2014

(C) International Osteoporosis Foundation and National Osteoporosis Foundation 2014

Gender is one of the strongest predictors of osteoporotic fracture risk, second only to ageing. A recent systematic review of worldwide epidemiology revealed that hip fracture incidence is about twofold lower in men compared to women, despite greater than tenfold variation between geographic regions [1]. This lower fracture incidence occurs despite persisting underdiagnosis and undertreatment of osteoporosis in men, which probably explains why hip fracture incidence may be decreasing in women but not men [2-5]. It is well known that men generally have a more robust body composition; even after correction for an average $10 \%$ greater height and bone length, men at the age of peak bone mass have $25 \%$ greater bone mineral content [6], almost $50 \%$ greater muscle mass and power and half the fat mass of women [7]. Conversely, late-onset male hypogonadism increases the risk of bone loss, muscle atrophy and fat accumulation [3, 8]. Understanding the underlying mechanisms involved in this gender dimorphism in body composition may thus identify additional

\section{R. Laurent • E. Gielen \\ Gerontology and Geriatrics, Department of Clinical and \\ Experimental Medicine, KU Leuven, Leuven, Belgium}

M. R. Laurent $\cdot$ E. Gielen $\cdot$ D. Vanderschueren

Centre for Metabolic Bone Diseases, University Hospitals Leuven, Leuven, Belgium

M. R. Laurent ( $ه)$

Laboratory of Molecular Endocrinology, Department of Cellular and

Molecular Medicine, KU Leuven, Herestraat 49, PO box 901,

3000 Leuven, Belgium

e-mail: Michael.Laurent@med.kuleuven.be

D. Vanderschueren

Clinical and Experimental Endocrinology, Department of Clinical

and Experimental Medicine, KU Leuven, Leuven, Belgium

D. Vanderschueren

Endocrinology and Andrology, University Hospitals Leuven,

Leuven, Belgium therapeutic targets not only for osteoporosis, but also for sarcopenia and obesity.

\section{Female sex steroids on a male genetic background}

Embryonically, we are all destined for female development, unless SRY (sex-determining region on the Y chromosome) and other transcription factors turn the bipotential gonads into testes capable of testosterone $(\mathrm{T})$ production. Studies on bone health in sexual medicine provide unique opportunities to examine whether sexual dimorphism is ultimately determined by sex chromosomes (genetic determinism) or sex steroids (endocrine regulation).

Van Caenegem et al. [9] are the first to study changes in areal and volumetric bone mineral density (aBMD, vBMD) and bone geometry in a representative, sizeable cohort (compared to the small number of subjects treated for gender dysphoria) of 49 male-to-female transsexual persons. The strength of this research paradigm is evident to anyone closely familiar with the spectacular bodily transformations experienced by subjects under cross-gender hormonal therapy. In a previous cross-sectional study by Van Caenegem et al., female-to-male transsexual persons had normal female body composition at baseline, but those on long-term $\mathrm{T}$ therapy exhibited increased lean body mass and grip strength, decreased fat mass with android distribution and increased radial cortical bone size with lower cortical vBMD [10]. The prospective design of their current study is however important because, compared to male controls, these male-to-female transsexual persons had baseline low aBMD due to somewhat lower periosteal circumference and lower trabecular vBMD, lower lean body mass, lower grip strength and muscle crosssectional area. This was probably related to lifestyle differences, as evidenced by less sports activities and lower serum 25-OH-vitamine D levels. 
The main finding of this study was that vBMD and cortical bone size remained stable (although trabecular vBMD slightly decreased) after 1 to 2 years of estrogen therapy with or without the anti-androgen cyproterone acetate (which brought $\mathrm{T}$ and estradiol (E2) levels within the normal female range). Bone turnover markers decreased, muscle mass and strength further decreased and fat mass increased. Another strength of this study is the use of peripheral quantitative computed tomography (pQCT) to avoid the limitations due to the projectional nature of conventional dual energy X-ray absorptiometry; aBMD apparently increased, but the pQCT data and lack of a prospective control group cast doubt on whether this is a true finding. Although this study has some additional limitations including short follow-up and use of lenient statistics, it offers reassurance about bone loss during cross-sex hormonal therapy in transgender subjects. But what are the broader implications of these results, if we look at the state of the science on how sex steroids regulate musculoskeletal maintenance?

Van Caenegem et al. rightly conclude that despite substantial muscle loss with androgen suppression, the prevention of bone loss in these male-to-female transsexual person is yet another attestation to the major role for estrogens in the male skeleton. Indeed, older men have higher E2 levels than postmenopausal women [6] because T levels (the substrate for E2 via aromatization) are well maintained in most elderly men. In our opinion however, two important questions remain: Is there an independent role for androgens in bone loss in older men? And secondly, are there other factors beyond androgens and estrogens responsible for skeletal sexual dimorphism and hypogonadal bone loss?

\section{Male bone maintenance: is there an independent role for androgens?}

\section{Preclinical studies}

Critics about direct androgen actions in bone could say that their effects may rely entirely on their myotrophic actions. Because it is quite difficult to study effects of androgens on bone independent of muscle-bone interactions in humans [10], preclinical models provide useful mechanistic insights. Earlier studies in androgen-resistant, $\mathrm{AR} / \mathrm{ER} \alpha$ knockout and overexpressing rodent models and in vitro studies suggest a dual mode of action by which both AR and ER $\alpha$ play a direct role in restraining male bone turnover and stimulating periosteal bone formation; there is even some animal evidence for a similar effect of both $\mathrm{AR}$ and $\mathrm{ER} \alpha$ in muscle and fat $[3,11$, 12]. However, these conclusions were reached in ubiquitous $\mathrm{AR} / \mathrm{ER} \alpha$ knockout models. In more recent conditional, cellspecific knockdown mouse models, male cortical and trabecular bone is directly regulated by $\mathrm{ER} \alpha$ in osteoprogenitor cells, osteoblasts and osteocytes [11], while AR in these bone cells has only a mild effect which is limited to trabecular bone. Nevertheless, AR overexpression in osteoblasts stimulates periosteal bone in the calvaria [13], which is unlikely to be explained by bone-muscle interactions. Conditional AR ablation in muscle [14, 15] and adipose tissue [16] also confirms a direct but humble role for androgens in these tissues. Thus, these conditional knockdown models do not fully reproduce the cortical bone deficits, sarcopenia and metabolic adversities observed in hypogonadal men or global ARKO male mice (both of which may have not only low T but also E2 levels) [11]. Non-aromatizable androgens clearly stimulate periosteal bone formation via AR in preclinical studies [17]; conditional genetic knockdown models may have been unable to confirm this role for AR in cortical bone because of the limitations of Cre-LoxP technology, or because the right target cells remain to be identified.

\section{Epidemiological studies}

Regarding the first question of independent effects of androgens and estrogens on ageing men's bone loss, we already have multiple lines of evidence already supporting the role of estrogens in male skeletal conservation. Firstly, dozens of observational and genetic studies in ageing men show an independent association between male bone mass, microarchitecture or fracture risk and circulating E2 levels or polymorphisms in the estrogen receptor alpha (ER $\alpha)$ or aromatase gene. The same associations with $\mathrm{T}$ levels or AR polymorphisms were however weak or disappeared after correction for estrogen effects in most studies [3, 11]. Nonetheless, some studies have shown an independent association of T with BMD at cortical sites or bone area [18, 19], muscle mass and strength, reduced fat mass $[20,21]$ and even decreased fracture risk, albeit mostly independent of aBMD [22, 23]. In two MrOS studies, low T was independently associated with bone loss and fractures but only in men with low E2 levels [24, 25]. Based on these results, Khosla proposed a model in which estrogens hold the dominant effect on male bone loss and fracture risk, whereas androgens further modulate this risk mainly via extraskeletal fracture determinants like muscle mass (which also determines cortical bone development) and risk of falls [26]. However, nearly all of these observational studies are limited by the small numbers of endpoints, variation of $\mathrm{T}$ and $\mathrm{E} 2$ levels within the normal range instead of more narrowly defined male hypogonadism [8], as well as inherent covariation between androgens, estrogens and sex hormone-binding globulin. Furthermore, there is growing evidence that calculated free or bioavailable serum sex steroid concentrations have serious limitations [27]. Studies with high-resolution pQCT have emerged, but we still need more prospective instead of cross-sectional studies. But in the end, observational studies cannot prove causality; both 
sex steroid concentrations and bone loss could be determined by other reproductive or hypothalamic signals (see next section on reproductive signals).

\section{Interventional studies}

A higher level of evidence is offered by placebo-controlled, randomized trials. In men with prostate cancer treated with androgen deprivation therapy (which is also brings estrogens in the postmenopausal range), selective estrogen receptor modulators (SERMs) have been shown to maintain aBMD and prevent vertebral fractures [28, 29]. In healthy adult male volunteers, aromatase inhibition [30] or treatment with nonaromatizable dihydrotestosterone [31], both of which increase androgen bioactivity but suppress estrogens, invoke bone loss. Although studies with gonadotropin-release hormone agonists and T or E2 replacement suggested that androgens maintained bone formation markers and estrogens suppressed bone resorption markers in men [32,33], another study contradicted this [34]. Recently, Finkelstein et al. conducted a similar, larger study with chemical castration and graded $\mathrm{T}$ replacement with or without aromatase inhibition [35]. They concluded that loss of androgens causes muscle loss whereas loss of estrogens increases adiposity in men with low $\mathrm{T}$. Bone microarchitectural outcomes have been published in abstract [36], showing again a dominant role for estrogens and not androgens. Yet, we should not ignore the fact that most of these interventions were acute and short-term, whereas transgender studies allow characterization of long-term effects. Importantly, the effect of physiological (or anabolic) $\mathrm{T}$ replacement doses in the context of normal E2 levels remains unclear (Table 1). Although it is important to realize that androgens cannot prevent bone loss due to near-total E2 deficiency, it may be more important to resolve the controversy surrounding the skeletal efficacy [37] as well as the cardiovascular safety of $\mathrm{T}$ replacement in frail older men at risk of osteoporosis [38]. The Testosterone Trials (NCT00799617) and especially the bone substudy will hopefully shed light on this matter. Hopefully thereafter, we can start thinking about studies to examine whether androgens offer selective benefits beyond their role in maintaining estrogen levels.

In summary, we believe the pendulum shouldn't swing too far. Even in the face of an overwhelming amount of data pointing towards the importance of aromatization and estrogens in the male skeleton, we need to distinguish between what we know, what we think we know, and what we still don't know. Although the obligation lies with andrology researchers to provide much needed evidence in humans, we would like to remind readers that lack of evidence for an effect - as for bone preservation despite loss of androgens in the controlled study by Van Caenegem et al.- - should not be taken as evidence for a lack of effect.

\section{Beyond sex steroids: bone's ties with reproduction}

A growing body of evidence supports an intimate relation between bone and gonadal factors beyond sex steroids. We refer the reader to a recent review for a more comprehensive discussion on this topic [39], and limit ourselves to a few examples. Direct bone cell regulation by gonadotropins has attracted considerable attention, but the presence of folliclestimulating hormone receptors in bone cells or a direct role independent of sex steroids remains controversial in both rodent and human studies [11, 40, 41]. Inhibin A however is a credible positive regulator of bone mass and turnover [40, $42,43]$. In the testis, Leydig cells have been suggested to express CYP2R1 which has been implicated in vitamin D 25hydroxylation [44], although definitive support for this mechanism remains lacking [39]. The increase in vitamin D despite gonadotropin suppression in the study by Van Caenegem et al.

Table 1 Evidence synopsis regarding the influence of androgens and estrogens on bone health in adult and elderly men

\begin{tabular}{|c|c|c|c|c|c|c|}
\hline & & aBMD & vBMD and structure & Bone turnover & Fractures & Muscle mass \\
\hline \multirow[t]{3}{*}{ Effect of deficiency (population setting) } & Low E2, normal or high $\mathrm{T}$ & $\downarrow[\mathrm{A}, \mathrm{B}]$ & $\downarrow[\mathrm{A}, \mathrm{B}]$ & $\uparrow[\mathrm{A}, \mathrm{B}]$ & $\uparrow[\mathrm{B}]$ & $=[\mathrm{A}, \mathrm{B}]$ \\
\hline & Low $\mathrm{T}$, low E2 & $\downarrow[\mathrm{A}, \mathrm{B}]$ & $\downarrow[\mathrm{A}, \mathrm{B}]$ & $\begin{array}{l}\uparrow[\mathrm{A}, \mathrm{B}] \\
(\downarrow \text { formation }[\mathrm{A}])\end{array}$ & $\uparrow \uparrow[\mathrm{B}]$ & $\downarrow[\mathrm{A}, \mathrm{B}]$ \\
\hline & Low T, normal E2 & $=[\mathrm{B}]$ & $?$ & ( $\downarrow$ formation $[\mathrm{A}]$ ) & $\uparrow[\mathrm{B}]$ & $\downarrow[\mathrm{A}, \mathrm{B}]$ \\
\hline \multirow[t]{5}{*}{ Effect of replacement (clinical setting) } & SERMs (ADT) & $\uparrow[\mathrm{A}, \mathrm{B}]$ & $?$ & $\downarrow[\mathrm{A}]$ & $\downarrow[\mathrm{A}]$ & $=$ \\
\hline & E2 (trans women) & $\uparrow[\mathrm{B}]$ & $=[\mathrm{B}]$ & $\downarrow[\mathrm{B}]$ & $?$ & $\downarrow[\mathrm{B}]$ \\
\hline & $\mathrm{T}$ (trans men) & $\uparrow[\mathrm{B}]$ & $\uparrow[\mathrm{B}]$ & $\uparrow[\mathrm{B}]$ & $?$ & $\uparrow[\mathrm{B}]$ \\
\hline & T (and E2) (elderly men) & $(\uparrow)[\mathrm{A}, \mathrm{B}]$ & $?$ & $\downarrow[\mathrm{A}, \mathrm{B}]$ & $?$ & $\uparrow[\mathrm{A}, \mathrm{B}]$ \\
\hline & SARMs/DHT with normal E2 & $?$ & $?$ & $?$ & $?$ & $?$ \\
\hline
\end{tabular}

$\downarrow$ decrease; $\uparrow$ increase; = no change; () equivocal evidence; ? no conclusive evidence available; [A] evidence from randomized controlled trials; [B] evidence from controlled intervention studies or large, population-based epidemiological studies in older men

SERMs selective estrogen receptor modulators, $A D T$ androgen deprivation therapy for prostate cancer 
[9] apparently contradicts a major role for gonadal vitamin D 25-hydroxylation, although this finding is probably confounded by vitamin D supplement prescription and lifestyle changes during clinical follow-up in these transgenders. Leydig cells also produce insulin-like peptide 3 which modulates osteoblast activity [39]. Critical transcription factors acting downstream of SRY to induce male sexual differentiation like SRYbox 9 (SOX-9) and the desert hedgehog gene have been associated with BMD in genome-wide meta-analysis [45]. SOX-9 in turn is essential for COL2A1 expression and chrondrogenesis. Finally, gonadal factors may not only improve bone health, but the causality may also lie in the opposite direction. The group of Karsenty recently showed that osteocalcin promotes testosterone biosynthesis in Leydig cells, and that heterozygous missense mutations in the osteocalcin receptor GPRC6A are a cause of primary testicular failure [46]. However, these findings remain to be viewed cautiously because of difficulties in translating these findings in other mouse models or in humans $[47,48]$.

We can conclude that bone has intricate and complex ties with gonadal and reproductive functions which include androgens, estrogens, transcription factors involved in sexual differentiation and possibly other gonadal endocrine factors, which however require further confirmation in further studies on male osteoporosis. Sexual and reproductive medicine may offer fertile grounds for further translational bone research.

Acknowledgments M.R. Laurent is a Fellow of the Research Foundation Flanders (FWO). D. Vanderschueren is a Senior Clinical Investigator of the University Hospitals Leuven Clinical Research Funds. This work was supported by grant OT/09/035 from KU Leuven and grant number G.0858.11 from the Research Foundation Flanders (FWO).

Conflicts of interest Michaël R. Laurent has received lecture fees from Flanders' Agricultural Marketing Board (VLAM). Evelien Gielen and Dirk Vanderschueren declare that they have no conflicts of interest.

\section{References}

1. Kanis JA, Oden A, McCloskey EV, Johansson H, Wahl DA, Cooper C (2012) A systematic review of hip fracture incidence and probability of fracture worldwide. Osteoporos Int 23(9):2239-2256

2. Hiligsmann M, Bruyère O, Roberfroid D, Dubois C, Parmentier Y, Carton J et al (2012) Trends in hip fracture incidence and in the prescription of antiosteoporosis medications during the same time period in Belgium (2000-2007). Arthritis Care Res (Hoboken) 64(5): 744-750

3. Laurent M, Gielen E, Claessens F, Boonen S, Vanderschueren D (2013) Osteoporosis in older men: recent advances in pathophysiology and treatment. Best Pract Res Clin Endocrinol Metab 27(4):527539

4. Amin S, Achenbach SJ, Atkinson EJ, Khosla S, Melton LJ 3rd (2014) Trends in fracture incidence: a population-based study over 20 years. J Bone Miner Res 29(3):581-589
5. Siggeirsdottir K, Aspelund T, Jonsson BY, Mogensen B, Gudmundsson EF, Gudnason V et al (2014) Epidemiology of fractures in Iceland and secular trends in major osteoporotic fractures 1989-2008. Osteoporos Int 25(1):211-219

6. Riggs BL, Khosla S, Melton LJ 3rd (2002) Sex steroids and the construction and conservation of the adult skeleton. Endocr Rev 23(3):279-302

7. Lindle RS, Metter EJ, Lynch NA, Fleg JL, Fozard JL, Tobin J et al (1997) Age and gender comparisons of muscle strength in 654 women and men aged 20-93 yr. J Appl Physiol (1985) 83(5):1581-1587

8. Tajar A, Huhtaniemi IT, O'Neill TW, Finn JD, Pye SR, Lee DM et al (2012) Characteristics of androgen deficiency in late-onset hypogonadism: results from the European Male Aging Study (EMAS). J Clin Endocrinol Metab 97(5):1508-1516

9. Van Caenegem E, Wierckx K, Taes Y, Schreiner T, Vandewalle S, Toye K, et al. (2014) Preservation of volumetric bone density and geometry in trans women during cross-sex hormonal therapy: a prospective observational study. Osteoporos Int. doi:10.1007/ s00198-014-2805-3

10. Van Caenegem E, Wierckx K, Taes Y, Dedecker D, Van de Peer F, Toye $\mathrm{K}$ et al (2012) Bone mass, bone geometry, and body composition in female-to-male transsexual persons after long-term cross-sex hormonal therapy. J Clin Endocrinol Metab 97(7):2503-2511

11. Laurent M, Antonio L, Sinnesael M, Dubois V, Gielen E, Claessens F et al (2014) Androgens and estrogens in skeletal sexual dimorphism. Asian J Androl 16(2):213-222

12. Callewaert F, Venken K, Ophoff J, De Gendt K, Torcasio A, van Lenthe GH et al (2009) Differential regulation of bone and body composition in male mice with combined inactivation of androgen and estrogen receptor-alpha. FASEB J 23(1):232-240

13. Wiren KM, Zhang XW, Toombs AR, Kasparcova V, Gentile MA, Harada $S$ et al (2004) Targeted overexpression of androgen receptor in osteoblasts: unexpected complex bone phenotype in growing animals. Endocrinology 145(7):3507-3522

14. Dubois V, Laurent MR, Sinnesael M, Cielen N, Helsen C, Clinckemalie L et al (2014) A satellite cell-specific knockout of the androgen receptor reveals myostatin as a direct androgen target in skeletal muscle. FASEB J 28(7):2979-2994

15. Ophoff J, Van Proeyen K, Callewaert F, De Gendt K, De Bock K, Vanden Bosch A et al (2009) Androgen signaling in myocytes contributes to the maintenance of muscle mass and fiber type regulation but not to muscle strength or fatigue. Endocrinology 150(8):3558-3566

16. McInnes KJ, Smith LB, Hunger NI, Saunders PT, Andrew R, Walker BR (2012) Deletion of the androgen receptor in adipose tissue in male mice elevates retinol binding protein 4 and reveals independent effects on visceral fat mass and on glucose homeostasis. Diabetes 61(5):1072-1081

17. Venken K, De Gendt K, Boonen S, Ophoff J, Bouillon R, Swinnen JV et al (2006) Relative impact of androgen and estrogen receptor activation in the effects of androgens on trabecular and cortical bone in growing male mice: a study in the androgen receptor knockout mouse model. J Bone Miner Res 21(4):576-585

18. Argoud T, Boutroy S, Claustrat B, Chapurlat R, Szulc P (2014) Association between sex steroid levels and bone microarchitecture in men: the STRAMBO study. J Clin Endocrinol Metab 99(4):1400-1410

19. Ward KA, Pye SR, Adams JE, Boonen S, Vanderschueren D, Borghs $\mathrm{H}$ et al (2011) Influence of age and sex steroids on bone density and geometry in middle-aged and elderly European men. Osteoporos Int 22(5):1513-1523

20. van den Beld AW, de Jong FH, Grobbee DE, Pols HA, Lamberts SW (2000) Measures of bioavailable serum testosterone and estradiol and their relationships with muscle strength, bone density, and body composition in elderly men. J Clin Endocrinol Metab 85(9):3276-3282

21. Renoud A, Ecochard R, Marchand F, Chapurlat R, Szulc P (2014) Predictive parameters of accelerated muscle loss in men-MINOS study. Am J Med 127(6):554-561 
22. Amin S, Zhang Y, Felson DT, Sawin CT, Hannan MT, Wilson PW et al (2006) Estradiol, testosterone, and the risk for hip fractures in elderly men from the Framingham Study. Am J Med 119(5):426433

23. Meier C, Nguyen TV, Handelsman DJ, Schindler C, Kushnir MM, Rockwood AL et al (2008) Endogenous sex hormones and incident fracture risk in older men: the Dubbo Osteoporosis Epidemiology Study. Arch Intern Med 168(1):47-54

24. LeBlanc ES, Nielson CM, Marshall LM, Lapidus JA, Barrett-Connor E, Ensrud KE et al (2009) The effects of serum testosterone, estradiol, and sex hormone binding globulin levels on fracture risk in older men. J Clin Endocrinol Metab 94(9):3337-3346

25. Woo J, Kwok T, Leung JC, Ohlsson C, Vandenput L, Leung PC (2012) Sex steroids and bone health in older Chinese men. Osteoporos Int 23(5):1553-1562

26. Khosla S (2010) Update in male osteoporosis. J Clin Endocrinol Metab 95(1):3-10

27. Laurent MR, Vanderschueren D (2014) Reproductive endocrinology: functional effects of sex hormone-binding globulin variants. Nat Rev Endocrinol. doi:10.1038/nrendo.2014.120

28. Smith MR, Fallon MA, Lee H, Finkelstein JS (2004) Raloxifene to prevent gonadotropin-releasing hormone agonist-induced bone loss in men with prostate cancer: a randomized controlled trial. J Clin Endocrinol Metab 89(8):3841-3846

29. Smith MR, Morton RA, Barnette KG, Sieber PR, Malkowicz SB, Rodriguez D et al (2010) Toremifene to reduce fracture risk in men receiving androgen deprivation therapy for prostate cancer. $\mathrm{J}$ Urol 184(4):1316-1321

30. Burnett-Bowie SA, McKay EA, Lee H, Leder BZ (2009) Effects of aromatase inhibition on bone mineral density and bone turnover in older men with low testosterone levels. J Clin Endocrinol Metab 94(12):4785-4792

31. Idan A, Griffiths KA, Harwood DT, Seibel MJ, Turner L, Conway AJ et al (2010) Long-term effects of dihydrotestosterone treatment on prostate growth in healthy, middle-aged men without prostate disease: a randomized, placebo-controlled trial. Ann Intern Med 153(10):621-632

32. Falahati-Nini A, Riggs BL, Atkinson EJ, O'Fallon WM, Eastell R, Khosla S (2000) Relative contributions of testosterone and estrogen in regulating bone resorption and formation in normal elderly men. $\mathrm{J}$ Clin Invest 106(12): 1553-1560

33. Leder BZ, LeBlanc KM, Schoenfeld DA, Eastell R, Finkelstein JS (2003) Differential effects of androgens and estrogens on bone turnover in normal men. J Clin Endocrinol Metab 88(1):204-210

34. Meier C, Liu PY, Ly LP, de Winter-Modzelewski J, Jimenez M, Handelsman DJ et al (2004) Recombinant human chorionic gonadotropin but not dihydrotestosterone alone stimulates osteoblastic collagen synthesis in older men with partial age-related androgen deficiency. J Clin Endocrinol Metab 89(6):3033-3041
35. Finkelstein JS, Lee H, Burnett-Bowie SA, Pallais JC, Yu EW, Borges LF et al (2013) Gonadal steroids and body composition, strength, and sexual function in men. N Engl J Med 369(11):1011-1022

36. Yu E, Wulcyzn K, Webb W, Perros N, Bouxsein M, Finkelstein J (2012) Hypogonadism with Estrogen Removal (HER): differential effects of androgens and estrogens on bone microarchitecture in adult men. J Bone Miner Res 27(Suppl 1)

37. Tracz MJ, Sideras K, Bolona ER, Haddad RM, Kennedy CC, Uraga MV et al (2006) Testosterone use in men and its effects on bone health. A systematic review and meta-analysis of randomized placebo-controlled trials. J Clin Endocrinol Metab 91(6):2011-2016

38. Basaria S, Coviello AD, Travison TG, Storer TW, Farwell WR, Jette AM et al (2010) Adverse events associated with testosterone administration. N Engl J Med 363(2):109-122

39. Ferlin A, Selice R, Carraro U, Foresta C (2013) Testicular function and bone metabolism - beyond testosterone. Nat Rev Endocrinol 9(9):548-554

40. Allan CM, Kalak R, Dunstan CR, McTavish KJ, Zhou H, Handelsman DJ et al (2010) Follicle-stimulating hormone increases bone mass in female mice. Proc Natl Acad Sci U S A 107(52): 22629-22634

41. Uihlein AV, Finkelstein JS, Lee H, Leder BZ (2014) FSH suppression does not affect bone turnover in eugonadal men. J Clin Endocrinol Metab 99(7):2510-2515

42. Perrien DS, Akel NS, Edwards PK, Carver AA, Bendre MS, Swain FL et al (2007) Inhibin A is an endocrine stimulator of bone mass and strength. Endocrinology 148(4):1654-1665

43. Perrien DS, Achenbach SJ, Bledsoe SE, Walser B, Suva LJ, Khosla S et al (2006) Bone turnover across the menopause transition: correlations with inhibins and follicle-stimulating hormone. J Clin Endocrinol Metab 91(5):1848-1854

44. Foresta C, Strapazzon G, De Toni L, Perilli L, Di Mambro A, Muciaccia B et al (2011) Bone mineral density and testicular failure: evidence for a role of vitamin D 25-hydroxylase in human testis. $\mathrm{J}$ Clin Endocrinol Metab 96(4):E646-E652

45. Estrada K, Styrkarsdottir U, Evangelou E, Hsu YH, Duncan EL, Ntzani EE et al (2012) Genome-wide meta-analysis identifies 56 bone mineral density loci and reveals 14 loci associated with risk of fracture. Nat Genet 44(5):491-501

46. Oury F, Ferron M, Huizhen W, Confavreux C, Xu L, Lacombe J et al (2013) Osteocalcin regulates murine and human fertility through a pancreas-bone-testis axis. J Clin Invest 123(6):2421-2433

47. Schwartz AV, Schafer AL, Grey A, Vittinghoff E, Palermo L, Lui LY et al (2013) Effects of antiresorptive therapies on glucose metabolism: results from the FIT, HORIZON-PFT, and FREEDOM trials. J Bone Miner Res 28(6):1348-1354

48. Andrews NA (2013) Skeletal regulation of glucose metabolism: challenges in translation from mouse to man. IBMS BoneKEy 10(353) doi:10.1038/bonekey.2013.87 